\title{
Rehabilitation in a primary care setting for persons with chronic illness - a randomized controlled trial
}

\author{
Julie Richardson ${ }^{1}$, Lori Letts', David Chan ${ }^{2}$, Paul Stratford', Carri Hand', David Price ${ }^{2}$, Linda Hilts ${ }^{2}$, \\ Liliana Coman ${ }^{1}$, Mary Edwards' ${ }^{1}$, Sue Baptiste ${ }^{1}$ and Mary Law ${ }^{1}$ \\ ${ }^{1}$ School of Rehabilitation, McMaster University, Hamilton, Ontario, Canada \\ ${ }^{2}$ Department of Family Medicine, McMaster University, Hamilton, Ontario, Canada
}

\begin{abstract}
Aim: The primary objective of this study was to determine whether adults with a chronic illness within a primary care setting who received a rehabilitation intervention in this setting showed greater improvement in health status and had fewer hospital admissions and emergency room visits compared with adults who do not receive the intervention. Background: More than half of Canadians (16 million people) live with chronic illness. Persons with chronic illness in primary care, especially older persons who are most at risk for functional decline, are currently not receiving effective management. Methods: A randomized controlled trial was used. A rehabilitation multi-component intervention was delivered by a physiotherapist (PT) and occupational therapist in a primary care setting and included collaborative goal setting for rehabilitation needs, a six-week chronic disease self-management (SM) workshop, referral to community programs and a web-based education programme. Findings: Three hundred and three patients participated, $n=152$ intervention group and $n=151$ in the control group. There was a significant difference between the groups for planned hospital days $(F=6.3, P=0.00)$ with an adjusted difference 0.60 day per person, and increased satisfaction with rehabilitation services however no difference on health status or emergency room visits. This rehabilitation intervention which had a strong SM component prevented planned hospitalizations that resulted in a conservative estimated cost saving from reduced hospitalizations of $\$ 65000$. Future research needs to examine which patient groups with chronic illness show positive responses to rehabilitation and self-management.
\end{abstract}

Key words: chronic illness; primary care; randomized controlled trial; rehabilitation

Received 14 May 2009; accepted 15 March 2010; first published online 22 June 2010

\section{Introduction}

Primary care is the first level of contact in the health system, where services are mobilized and coordinated to promote health, prevent illness, and manage chronic illness (Health Canada, 2001).

Correspondence to: Dr Julie Richardson, Associate Professor, School of Rehabilitation Science, McMaster University, IAHS 403, 1400 Main Street West, Hamilton, ON L8S 1C7, Canada. Email: jrichard@mcmaster.ca
It represents longitudinal, comprehensive and person-centred care where health care needs are addressed by preventive, curative or rehabilitative care or referral to other services (Franks et al., 1993). Chronic disease is the leading cause of death $(60 \%)$ and disability (43\%) worldwide (World Health Organization, 2007). In Canada, over twothirds of the total deaths result from cardiovascular disease, diabetes, cancer and respiratory illness and more than half of Canadians (16 million people) live with chronic illness (Dubois, 2003). The 
future of primary care lies in its ability to meet the needs of persons who are chronically ill (Anderson and Wagner, 2003). Persons with chronic illness, especially older persons who are most at risk for functional decline, are currently not receiving effective management (Grumbach and Bodenheimer, 2002). The principles attributed to primary care, accessibility, continuity, comprehensiveness, and coordination are also needed for the care of the chronically ill. Primary care provides the best service to those with chronic illness who experience comorbidity and non-acute periods. Successful care with this clinical population requires coordination, expertise in behavioural change, and self-management (SM) support (Anderson and Wagner, 2003).

Persons with access to primary care report greater satisfaction with medical care (Hayward et al., 1991), fewer hospital admissions (Weinberger et al., 1996), and less use of emergency room care than those without access (Hurley et al., 1989). Persons followed by a patient care provider (PCP) are $50 \%$ less likely to have a preventable hospital admission and fewer persons show a decline in health status than those who were not followed by a PCP. Patients who use emergency services for primary care are more ill on admission (Franks et al., 1993).

Many roles in primary care could be performed by health professionals other than physicians and nurses (Moore and Showstack, 2003). An international review of primary care often cited physiotherapy as a service offered within primary care, but did not describe the services offered or how these were integrated (Marriot and Mable, 2000). A study from two rural Ontario primary care practices found that rehabilitation services (monitoring and treating chronic illness and disability) were more frequently provided by physicians while nurse practitioners provided services related to prevention. Monitoring of stable chronic illness was the category to which most resources were allocated (Way et al., 2001).

There have been several evaluations of collaborative models of primary care related to the health of older adults with chronic illness. (Beck et al., 1997) (Leveille et al., 1998; Coleman et al., 1999; Reuben et al., 1999; Burns et al., 2000; Boult et al., 2001; Schraeder et al., 2001). Five out of the seven studies resulted in some favourable outcomes, one team which included a rehabilitation professional physiotherapist (PT) (Reuben et al.,
1999) also reported a significant improvement in physical functioning for the participants. The PT's role in these trials involved assessments and interventions for persons who had fallen or were experiencing impaired mobility. There has been limited research to investigate the effectiveness of rehabilitation interventions in primary care settings to address health needs of people with chronic illness.

This current study addresses the healthcare needs of persons with chronic illness who have the greatest burden of suffering and highest health care costs. The study was undertaken in the context of the Canadian Health Care system in the province of Ontario. The Canadian Health Act provides universal healthcare coverage, which focuses on hospital and physician services. Provincial governments are responsible for organizing public insurance systems. There is minimal support for chronic disease SM through community and non-profit organizations, these are most frequently disease specific programmes such as the Arthritis SM provided by the Arthritis Society. Coverage for rehabilitation services for people with chronic diseases is also variable, since hospital rehabilitation outpatient services have been almost eliminated through healthcare reforms. In community settings, rehabilitation services, especially physiotherapy, are provided through private clinics, with most people accessing these services through third party coverage such as employer benefits. Since many people with chronic conditions are on disability support, they have minimal or no access to rehabilitation chronic disease management. The intervention is directed at health promotion, disease and injury prevention and education through physiotherapy and occupational therapy interventions, and includes priority care for high-risk patients.

\section{Objectives}

The primary objective was to determine whether adults with a chronic illness receiving care in a primary care (PC) setting and who received a rehabilitation intervention in this setting showed greater improvement in health status and had fewer hospital admissions and emergency room visits compared with adults who did not receive the intervention. The secondary objectives were to determine whether the same group showed 
greater improvement in physical functional status, activities of daily living and instrumental activities of daily living, participation, and decreased falls, showed greater improvement in self-efficacy, and increased home safety and reported greater satisfaction with care compared with adults who did not receive the intervention.

\section{Design}

A randomized controlled trial design was used to test the difference between patients who received a rehabilitation intervention in a primary care setting (intervention group) compared with patients who did not receive the intervention (control group, CG).

\section{Methods}

Patients who were eligible were invited to participate in the study and were assessed for risk of functional decline (a score of $<60$ The Late Life Function and Disability Index (LLFDI) (Jette et al., 2002), falling (a fall in the previous 12 months), or a health event or hospitalization (an eight item questionnaire was used to classify patients into risk groups). The questionnaire enabled the calculation of the probability of repeated admission and functional decline $\left(P_{\text {ra }}\right)$ and identified persons who were more likely to use healthcare services (Boult et al., 1994; Pacala et al., 1995; Coleman et al., 1998). After patients gave consent, the study coordinator arranged baseline assessment and subsequent randomization. We stratified participants according to age (44-64 years, 65+ years) and physical function. An independent method centre at McMaster University held the code, which was computer generated and stratified for age and function. When the study coordinator had established eligibility to participate in the study and gained consent she contacted the methods centre by phone to receive the allocation for each participant for the study.

\section{Setting}

The intervention was delivered at a Family Health Centre in Hamilton, Ontario (a Health Service Organization) where an interdisciplinary team with seven full-time physicians and 16 resident physicians served approximately 15000 patients. The Hamilton Health Sciences Research Ethics Board awarded ethics approval for this study.

\section{Participants}

Persons were eligible to participate in the trial if they were $\geqslant 44$ years of age, had at least one of the following chronic diseases: back pain, diabetes, multiple sclerosis, stroke, Parkinson's disease, cardiovascular disease (cardiac heart failure (CHF), hypertension, angina) chronic obstructive pulmonary disease, asthma, fibromyalgia, cancer, arthritis, and obesity: had at least four visits to the family physician in the previous year, did not have dementia and were not residing in a longterm care facility. Patients were selected from the practice database of one of the teams in the practice described above and were invited to participate in the trial. A priori sample size and power estimates were based on an eight-point difference in the means on the Short Form-36 (SF-36) between treatment groups as an important clinical difference which gave a standardized effect size of $d=0.3$. Setting the alpha at 0.05 and beta at 0.2 (power 0.8) with a dropout rate of $10 \%$, the total sample size required was $n=308$. If patients consented a PT or an occupational therapist (OT) blinded to the intervention allocation assessed the participant in their home and the results were recorded onto laptops and then downloaded onto a server at the practice. Patients were assessed at three points in time at baseline, six and nine months. The therapists remained blinded for all the three assessment times.

\section{Instruments and measures}

The SF-36 was used to assess the participants' health status. It has 36 items and measures three attributes (functional status, well being, and overall perceptions of health) and eight health concepts. This assessment demonstrated excellent internal consistency and reliability in primary care, Cronbach's alpha: $>0.85$ and test-retest reliability ICC: $>0.75$, for all dimensions except social functioning. It also demonstrated good construct validity and distinguished between groups with expected health differences (Brazier et al., 1992). The instrument has been shown to be responsive over a 36-month period with effect sizes from 0.2 to 0.7 in participants with physical and psychiatric morbidity (Hemingway et al., 1997).

The LLFDI was used to assess function. It is designed to assess meaningful change in functional 
limitations and disability in community dwelling older adults. Test-retest reliability over a 1-3-week period was high $(\mathrm{ICC}=0.91-0.98)$ (Haley et al., 2002; Jette et al., 2002). The Two Minute Walk Test is an objective measure of functional exercise capacity. Correlations between the 2- and 6-min walk $(r=0.89)$ and the 2- and 12-min walk $(r=$ $0.86)$ indicate that they are similar measures of exercise tolerance (Butland et al., 1982). The Lower Extremity Performance Test includes an eight-foot walk, balance test, and repeated chair stands. Correlations between observers of more than 0.93 for walking speed and test-retest correlations of more than 0.89 for walking speed, 0.73 for repeated rising from a chair and 0.97 for balance have been reported (Guralnik et al., 1994). Participants were asked if they had any falls, accidents, or injuries in the past 12 months and if so, whether they received medical attention. The Home Falls and Accidents Screening Tool (Home Fast) was used to assess home safety (Mackenzie et al., 2000). Each of the 25 items concerning home safety is assessed on an 11-point risk scale. The Home Fast has two factors, environmental and functional issues and the testretest reliability for these factors are $R>0.75$ and $R=0.4-0.7$, respectively. The predictive validity of the items for falling ranged between loose mats $\mathrm{RR}=1.4$ and bed transfers $\mathrm{RR}=2.3$ (Mackenzie et al., 2002a, 2002b). Grip strength was used as a proxy of overall muscle strength on both hands using a Jaymar dynamometer (Rantanen et al., 2003).

SM and self-efficacy (SE) measures were used to evaluate the effect of the chronic disease self management program (CDSMP). Assessment of internal consistency for these measures ranged from $0.7-0.8$ (SM) and 0.8-0.9 (SE) and test-retest reliability $R=0.6-0.9(\mathrm{SM})$ and $R=0.7-0.9(\mathrm{SE})$ (Lorig et al., 1996).

The patient satisfaction questionnaire (PSQ-18) was used to assess the satisfaction of participants in both groups. (Marshall and Hays, 1994; Pacala et al., 1995; Morishita et al., 1998), an 18 item instrument with seven sub scales. The sub scales have internal consistency $0.64-0.77$ and correlations of 0.9 or higher with the sub scales of the PSQ-III. Minor modifications were made to this scale so that the questions referred to satisfaction with rehabilitation services rather than medical services.

The caregiver strain index was used to assess whether the caregiver experienced less strain as a result of the rehabilitation intervention. It is a
13 item tool that measures strain related to care provision. There is at least one item for each of the following areas: employment, financial, physical, social, and time. Positive responses to seven or more items indicate a greater level of strain. It has a high level of internal consistency $(\alpha=0.86)$, test-retest reliability ICC $=0.93(95 \%$ CI 0.84-0.97) and construct validity supported by correlations with physical and emotional health of the caregiver and subjective views of the caregiver (Robinson, 1983; Post et al., 2007).

Information regarding planned days in hospital and emergency room visits was also collected at baseline and subsequent assessments by selfreport, but not verified by hospital records.

\section{Intervention}

The model of service delivery followed the model of client-centred rehabilitation service delivery, which involves collaborative goal setting between the therapist and the patient to address impairments, activity limitation, and participation restriction (Hopman et al., 2000). The intervention also addressed components of the expanded chronic illness model including self-management, information systems, and decision support (Barr et al., 2003). A full-time PT and an OT were integrated into the practice and provided the rehabilitation intervention. All participants in the intervention group underwent a screening/ monitoring process to identify persons at risk for functional decline. If they were deemed at risk they were given a priority for this intervention. The multi-component intervention delivered by the PT and OT included collaborative goal setting for rehabilitation needs, individual treatment as needed, a six-week group SM workshop (CDSMP) based on the Stanford Model. The participants received some extra information within the workshop about the link between rehabilitation and chronic disease management, some information about FITT principles for exercise (frequency, intensity, time, and type) and assistive devices. For those persons who could not participate an individual approach to SM was integrated into the treatment intervention, referral to community programs, and a web-based education programme, www.iamable.ca which held disease-specific information and information about rehabilitation principles. See Figure 1 for model of the intervention. 


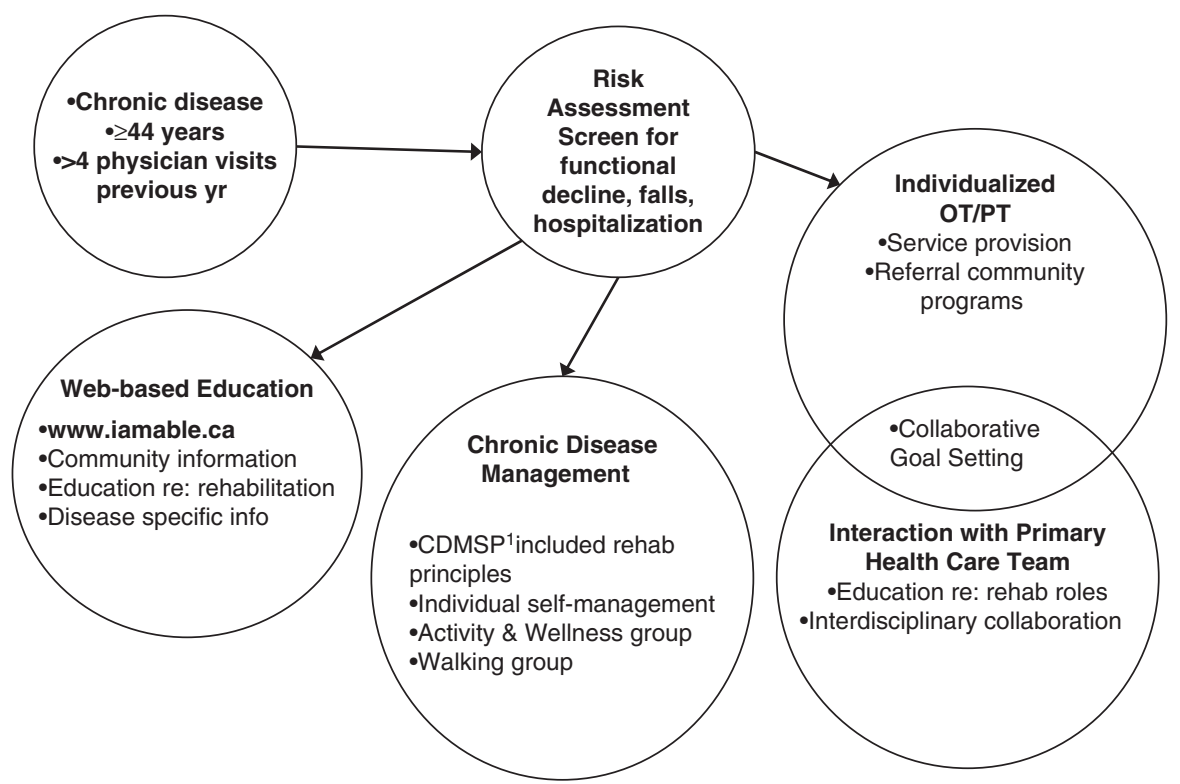

Fig. 1 Primary care model for rehabilitation intervention

The CG received usual care, which meant that they did not receive rehabilitation services within the primary care setting where the trial was conducted, but could access these services within the community if they were available as they would normally.

\section{Analysis}

An intention to treat approach was used for all analyses using SPSS version 15.0. We calculated the domain and overall scores for each instrument for the randomized groups. Missing data was determined to be missing at random and for data that was missing the last value was carried forward. $\chi^{2}$ tests and independent $t$-tests were used for categorical and continuous variables, respectively, to compare differences between the groups at baseline. We examined the time and treatment effects and their interaction using analyses of variance for the continuous variables. Each analysis was adjusted for five covariates that included the outcome measure baseline score, age group, gender, LLFDI Function Score at baseline, and the sum of two risk factors (fall and risk of hospitalization). For the dichotomous outcomes that included falls and priority rating we used logistic regression adjusting for the same covariates and the ordinal variables were analysed using a Mann-Whitney $U$-test.

\section{Results}

Three hundred and three participants agreed to participate in the study $(n=152$ intervention group and $n=151$ in the CG), approximately $13 \%$ in the intervention group and $9 \%$ in the $\mathrm{CG}$ did not complete final assessments at Time three (see Figure 2). Each intervention group participant was seen by both OT and the PT within this multi-component intervention and one of the disciplines was responsible for overall coordination of the intervention delivered to each participant. The occupational therapy intervention consisted of individual assessments, psychosocial intervention, equipment, household management, group self-management, and other group activities. The physiotherapy intervention consisted of individual assessment, acupuncture, exercises, individual assessment, individual education, balance and gait training, and group self-management. The percentage of time spent delivering these various activities is shown in Table 1. Eighty-two people (63\%) attended the SM workshops and 23 participants, 


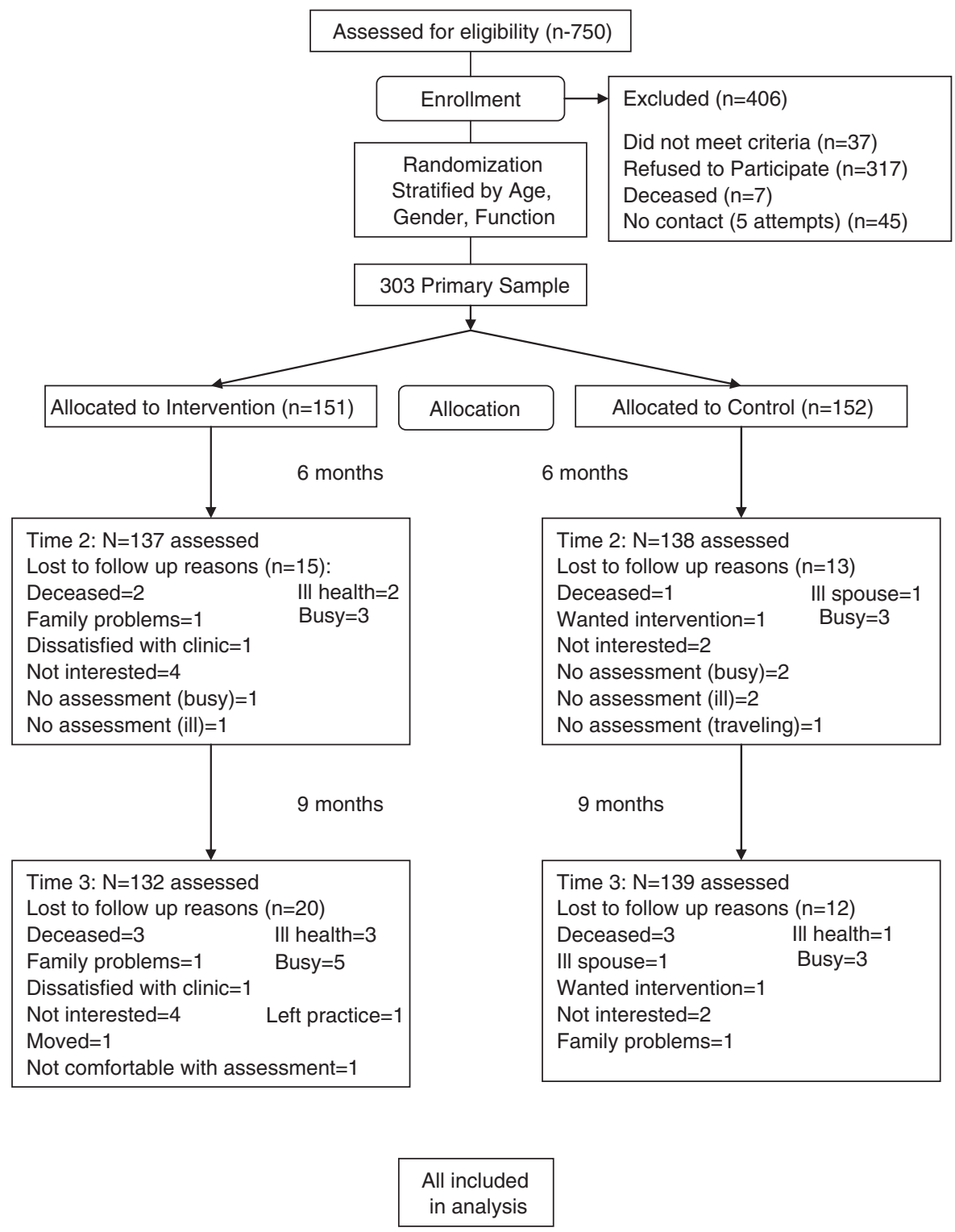

Fig. 2 Flow of participants through the study

approximately $15 \%$, received individual SM instruction. The PT provided 137 assessments, and a total of 865 visits, an average of approximately six visits per person and the average length of each visit was $35 \mathrm{~min}$. Eighteen percent of the total time which the PT spent in patient care was directed at self management, the remainder of the time $82 \%$ was spent delivering interventions which included exercise, balance and gait training, manual techniques, modalities, acupuncture, and individual assessment. The OT provided a total of 132 assessments and 358 visits, an average of approximately four visits per person while the average length of each visit was $57 \mathrm{~min}$. Twenty three percent of the total time that the OT spent on patient care was directed at self management and the 
Table 1 Distribution of direct time for PT and OT

\begin{tabular}{lllr}
\hline Activities physiotherapy & $\%$ & Activities occupational therapy & $\%$ \\
\hline Individual assessment & 17 & Individual assessment & 25 \\
Group self-management & 18 & Group self-management & 23 \\
Acupuncture & 16 & Activity and wellness group & 10 \\
Exercises & 16 & Psycho-social intervention & 10 \\
Individual education & 13 & Equipment/devices & 6 \\
Manual techniques & 5 & Walking group & 5 \\
Balance and gait training & 4 & Household management & 3 \\
Modalities & 3 & ADL/IADL & 3 \\
Psychosocial & 2 & Functional restoration & 3 \\
Consultation & 2 & Individual education & 3 \\
Wellness and lifestyle changes & 1 & Consultation & 3 \\
Equipment/devices/materials & 1 & Other & 6 \\
\hline
\end{tabular}

$\mathrm{PT}=$ physiotherapist; OT = occupational therapist; $\mathrm{ADL}=$ activities of daily living; $\mathrm{IADL}=$ instrumental activities of daily living.

Table 2 Chronic conditions by group

\begin{tabular}{|c|c|c|c|c|c|c|}
\hline & \multicolumn{2}{|c|}{ Intervention } & \multicolumn{4}{|c|}{ Control } \\
\hline & $n$ & $\%$ & $n$ & $\%$ & $x^{2}$ & $P$ \\
\hline Angina & 20 & 13.2 & 17 & 11.3 & 0.19 & 0.66 \\
\hline Congestive heart failure & 6 & 3.9 & 8 & 5.7 & 0.33 & 0.57 \\
\hline Hypertension & 89 & 58.6 & 89 & 58.9 & 0.08 & 0.66 \\
\hline Heart disease & 22 & 14.5 & 31 & 20.5 & 1.9 & 0.16 \\
\hline Diabetes & 36 & 23.7 & 36 & 23.8 & 0.004 & 0.95 \\
\hline Arthritis & 60 & 39.5 & 58 & 38.0 & 0.002 & 0.96 \\
\hline Stroke & 6 & 3.9 & 6 & 4.0 & 0.12 & 0.73 \\
\hline Cancer & 22 & 14.5 & 24 & 15.9 & 0.19 & 0.66 \\
\hline Parkinson's & 1 & 0.7 & 1 & 0.7 & 0.00 & 0.99 \\
\hline Chronic Obstructive Pulmonary Disease & 12 & 7.9 & 18 & 11.9 & 1.4 & 0.23 \\
\hline Fibromyalgia & 5 & 3.3 & 10 & 6.6 & 1.8 & 0.66 \\
\hline Multiple sclerosis & 1 & 0.7 & 3 & 2.0 & 1.04 & 0.31 \\
\hline Asthma & 17 & 11.2 & 27 & 17.9 & 2.7 & 0.09 \\
\hline Back pain & 69 & 45.4 & 77 & 51.0 & 0.95 & 0.33 \\
\hline Obesity & 62 & 40.8 & 62 & 41.1 & 0.009 & 0.92 \\
\hline
\end{tabular}

remainder of the time $77 \%$ was spent delivering interventions which included individual assessment psychosocial activities, prescribing equipment and devices and addressing household management. There were 1709 hits to the www.iamable.ca by the end of the study. The most frequently reported conditions for both groups were arthritis and hypertension and there was no significant difference between the groups for any disorder (see Table 2) or in the frequency of comorbidity.

There were no significant differences between the groups on any of the demographic variables (Table 3) or main outcomes at baseline. Fortyfour percent of the intervention group and $38 \%$ of the CG had a yearly income $\$ 40000$ or less. This is a lower income level than the city of Hamilton which is $\$ 57700$ or the Ontario average of $\$ 66000$ indicating that the sample holds a lower socio-economic status (http://www. hamiltonccac.ca/n_mcquesten14.html\#2). At the end of the trial there was no difference between the groups on health status as measured by the SF-36, physical component intervention group (IG) mean $=42, \mathrm{SD}=11.8, \quad \mathrm{CG}$ mean $=43.1$, $\mathrm{SD}=11.9, F=2.56, P=0.11$ and the mental component $\mathrm{IG}$, mean $=51, \mathrm{SD}=11.8, \mathrm{CG}$ mean $=$ 50.6, $F=0.01, P=0.93$, there was a gender $\times$ age interaction on the physical component, $F=9.83$, 
Table 3 Baseline demographic characteristics of participants

\begin{tabular}{|c|c|c|c|c|c|}
\hline & \multicolumn{2}{|c|}{ Intervention ( $n=152)$} & \multicolumn{2}{|c|}{ Control $(n=151)$} & \multirow[t]{2}{*}{ Comparison of groups } \\
\hline & $n$ & $\%$ & $n$ & $\%$ & \\
\hline \multicolumn{6}{|l|}{ Age (years) } \\
\hline $46-54$ & 46 & 30.3 & 40 & 26.5 & $t=0.23^{\mathrm{a}}$ \\
\hline $55-64$ & 40 & 26.3 & 46 & 30.5 & $P=0.82$ \\
\hline $65-74$ & 24 & 15.8 & 33 & 21.8 & \\
\hline 75-95 & 42 & 27.6 & 32 & 21.2 & \\
\hline \multicolumn{6}{|l|}{ Gender } \\
\hline Male & 54 & 35.5 & 57 & 37.7 & $x^{2}=0.16$ \\
\hline Female & 98 & 64.5 & 94 & 62.3 & $P=0.46$ \\
\hline \multicolumn{6}{|l|}{ Education } \\
\hline Completed elementary or less & 24 & 14.5 & 10 & 6.6 & $x^{2}=5.67$ \\
\hline Secondary school education & 63 & 41.2 & 72 & 47.0 & $P=0.46$ \\
\hline University education & 25 & 16.3 & 28 & 18.5 & \\
\hline \multicolumn{6}{|l|}{ Yearly income } \\
\hline Below $\$ 20000$ & 23 & 15.1 & 20 & 13.2 & $x^{2}=5.27$ \\
\hline$\$ 20000-\$ 30000$ & 21 & 13.8 & 24 & 15.9 & $P=0.51$ \\
\hline$\$ 30000-\$ 40000$ & 23 & 15.1 & 14 & 9.3 & \\
\hline$\$ 40000-\$ 50000$ & 13 & 8.6 & 14 & 9.3 & \\
\hline Over $\$ 50000$ & 43 & 28.3 & 52 & 34.4 & \\
\hline Do not know/refused to answer & 29 & 19.0 & 27.0 & 17.9 & \\
\hline \multicolumn{6}{|l|}{ Marital status ${ }^{c}$} \\
\hline Married/living together & 93 & 62.5 & 103 & 68.1 & $x^{2}=0.99$ \\
\hline Separated/divorced & 20 & 13.2 & 18 & 11.9 & $P=0.61$ \\
\hline Widowed/never married & 35 & 23.0 & 29 & 19.3 & \\
\hline \multicolumn{6}{|l|}{ Accommodation } \\
\hline House & 127 & 83.6 & 128 & 84.8 & $x^{2}=0.09^{d}$ \\
\hline Apartment & 24 & 15.8 & 22 & 14.6 & $P=0.66$ \\
\hline Senior's home & 1 & 0.7 & 1 & 0.7 & \\
\hline \multicolumn{6}{|l|}{ Risk assessment } \\
\hline At risk & 96 & 63.2 & 99 & 65.6 & $x^{2}=0.19$ \\
\hline Not at risk & 65 & 36.8 & 52 & 34.4 & $P=0.66$ \\
\hline \multicolumn{6}{|c|}{ Help available from household member } \\
\hline Yes & 86 & 56.6 & 88 & 58.3 & $x^{2}=0.79$ \\
\hline No & 37 & 24.3 & 31 & 20.5 & $P=0.68$ \\
\hline Do not need help & 29 & 19.1 & 32 & 21.2 & \\
\hline
\end{tabular}

a Interval data used for test.

${ }^{\mathrm{b}}$ Not including non-responders; intervention $n=151$, control $n=150$.

c Intervention $n=150$, control $n=150$.

d Not including senior's home.

$P=0.002$ (see Table 4). There was also no significant difference between the groups on the LLFDI total score or either of the subscale scores. There was a significant difference between the groups for planned hospital days ${ }^{1}$ IG mean $=$ $0.00, \mathrm{SD}=0.0, \mathrm{CG}$ mean $=0.4, \mathrm{SD}=1.8, F=6.4$, $P=0.00$ with an adjusted difference 0.60 day per

\footnotetext{
${ }^{1}$ In the last nine months did you ever spend one or more nights in the hospital, due to a planned hospitalization, (eg, hernia or knee surgery). If yes, how many times (total number of days).
}

person. There was no significance between group differences for emergency room visits. The IG reported fewer falls at time three, $n=33$ compared with $n=39, P=0.60$ and there were also fewer home hazards for the IG mean $=3.8$ compared with $\mathrm{CG}$ mean $=4.1, F=0.86, P=0.35$ (see Table 4). There were no significant differences between the groups on any of the performance measures. Communication with physician approached significance IG mean $=3.0, \mathrm{SD}=1.3$, $\mathrm{CG}=2.7, \mathrm{SD}=1.4, F=3.35, P=0.07$. The caregivers in the IG also reported lower scores on the 
Strain Index IG, mean $=2.5, \mathrm{SD}=1.6$, mean $=$ $5.1, \mathrm{SD}=2.3, F=1.73, P=0.24$, however the number of caregivers ( $n=9$ intervention group, $n=13 \mathrm{CG}$ ) was not adequately powered to assess any significant differences between the two groups. The intervention group rated their satisfaction with rehabilitation services higher than the CG, mean $=3.6$ versus mean $=3.2, t=-4.69$, $P=0.00$, (see Table 5).

\section{Discussion}

The primary objective of the study was to determine whether adults with a chronic illness $\geqslant 44$ years of age showed improved health status when they received rehabilitation within a primary care setting of a Family Health Centre compared with persons without the intervention. This is the first trial examining a rehabilitation intervention delivered in a primary care setting for persons with chronic disease reported in the literature. More than half of the eligible persons approached agreed to participate. Although there was no difference in health status or physical functioning as measured by self-report or performance measures at the end of the trial, there was a difference between groups on health service utilization for planned hospital days that may have been the result of participants' improved self-management. This difference in planned hospital days as a conservative estimate would result in a daily saving of CDN $\$ 490$ per person ( 0.60 of daily cost of hospital admission at the time of study completion) and an overall cost saving from reduced hospitalizations of $\$ 65000$ for the intervention group. These cost savings should be considered along with the costs associated with the trial, which were principally the costs of the therapists providing the intervention. The exact cost of the therapists' time associated with providing the intervention is difficult to determine since many of their activities related to study activities and also providing services for the first time in a primary care setting (Table 1).

The results of this study are similar to those reported by Scott et al. (2004) that examined a group outpatient visit model for chronically ill older persons who were members of a health maintenance organization (Scott et al., 2004). Patients in this study attended monthly group visits held by their primary care physicians. This study also showed improved patient satisfaction, fewer hospital admissions, and increased SE in communicating with the physician. No changes were seen in function or health status. Other studies have also shown increased patient satisfaction, but no change in physical function scores (Coleman et al., 1999). A recent study found that a programme to improve the management of chronic disease at community health centres significantly improved the processes of care for diabetes and asthma, but not hypertension, however, there was no improvement in the clinical outcomes studied (Landon et al., 2007). It has been suggested that the timeframe for clinical trials involving persons with chronic illness may need to be longer to observe true effects for certain clinical outcomes and this maybe the case with physical functioning (Pincus, 2002).

The participants in the intervention group reported greater satisfaction with rehabilitation services compared with the CG who had to seek these services outside the practice setting indicating that participants were positive about the rehabilitation services they received within the primary care setting where they received other health services (Table 5). Previous research has shown that patients with an increased number of symptoms rate their satisfaction with services lower (Hall et al., 1993). It has been suggested that the measurement of satisfaction with rehabilitation services maybe different than satisfaction with other areas of health care since the restoration of function occurs over a prolonged period of time (Keith, 1998). The caregivers of the participants in the intervention group showed less caregiver strain than caregivers in the CG. The difference was not statistically significant because the outcome was underpowered, however the results suggest a need for further research on the effect of rehabilitation interventions on caregivers.

There was no difference between the groups on either component of the SF-36, both groups were fairly low functioning on the physical and mental components. Further analysis of the age $\times$ gender interaction on the physical component showed that it was the younger women, in the intervention group, whose physical functioning scores showed the most improvement. Men in the older age group were least likely to improve. The lack 
Table 4 Mean (SD) and ANCOVA by group for self reported outcomes, utilization and performance measures

\begin{tabular}{|c|c|c|c|c|c|c|c|}
\hline \multirow[t]{2}{*}{ Scale } & \multicolumn{2}{|c|}{$\begin{array}{l}\text { Time 1: mean (SD) } \\
\text { Baseline }\end{array}$} & \multicolumn{2}{|c|}{$\begin{array}{l}\text { Time 3: mean (SD) } \\
15 \text { months }\end{array}$} & \multicolumn{2}{|l|}{ Factor $=$ Group } & \multirow[b]{2}{*}{$\begin{array}{l}\text { Other significant fixed } \\
\text { factors or interaction terms }\end{array}$} \\
\hline & $\begin{array}{l}\text { Intervention } \\
(n=152)\end{array}$ & $\begin{array}{l}\text { Control } \\
(n=151)\end{array}$ & $\begin{array}{l}\text { Intervention } \\
(n=132)\end{array}$ & $\begin{array}{l}\text { Control } \\
(n=139)\end{array}$ & $F$-value & $P$-value & \\
\hline $\begin{array}{l}\text { FDI function } \\
\text { FDI disability frequency } \\
\text { FDI disability limitation }\end{array}$ & $\begin{array}{l}61.85(12.68) \\
50.47(5.97) \\
71.86(15.01)\end{array}$ & $\begin{array}{l}59.93(12.79) \\
50.68(5.60) \\
70.45(16.42)\end{array}$ & $\begin{array}{l}61.3(12.3) \\
49.9(6.1) \\
75.0(17.0)\end{array}$ & $\begin{array}{l}62.3(15.8) \\
50.0(5.6) \\
75.1(18.2)\end{array}$ & $\begin{array}{l}2.89 \\
0.03 \\
0.23\end{array}$ & $\begin{array}{l}0.09 \\
0.86 \\
0.63\end{array}$ & $\begin{array}{l}\text { Age, age } \times \text { gender } \\
\text { Age, group } \times \text { age } \\
\text { Gender, }\end{array}$ \\
\hline $\begin{array}{l}\text { SF-36 physical component } \\
\text { SF-36 mental component }{ }^{\mathrm{a}} \\
\text { Number emergency visits } \\
\text { Planned days in hospital } \\
\text { Fallen in last } 9 \text { months? }\end{array}$ & $\begin{array}{l}41.91(10.56) \\
49.37(12.14)\end{array}$ & $\begin{array}{l}40.88(12.0) \\
50.08(11.25)\end{array}$ & $\begin{array}{c}42.0(11.8) \\
51.0(11.8) \\
0.2(0.9) \\
0.0(0.0)\end{array}$ & $\begin{array}{c}43.1(11.9) \\
50.6(11.8) \\
0.2(0.5) \\
0.4(1.8)\end{array}$ & $\begin{array}{l}2.56 \\
0.01 \\
0.28 \\
6.4\end{array}$ & $\begin{array}{l}0.11 \\
0.93 \\
0.60 \\
0.01\end{array}$ & $\begin{array}{l}\text { group } \times \text { gender } \times \text { age } \\
\text { Gender } \times \text { age }\end{array}$ \\
\hline $\begin{array}{l}\text { Yes } \\
\text { No }\end{array}$ & $\begin{array}{r}40 \\
112\end{array}$ & $\begin{array}{r}50 \\
101\end{array}$ & $\begin{array}{c}33 \\
94\end{array}$ & $\begin{array}{l}39 \\
97\end{array}$ & $\operatorname{Exp}(B)=1.16$ & 0.60 & goodness of fit $P=0.96$ \\
\hline $\begin{array}{l}\text { Average dominant grip strength }(\mathrm{kg})^{c} \\
\text { Average non-dominant grip strength }\end{array}$ & $\begin{array}{l}25.36(11.24) \\
24.28(10.74)\end{array}$ & $\begin{array}{l}25.41(11.31) \\
23.40(10.94)\end{array}$ & $\begin{array}{l}25.3(13.5) \\
23.1(11.4)\end{array}$ & $\begin{array}{l}26.6(16.2) \\
24.6(14.5)\end{array}$ & $\begin{array}{l}0.48 \\
2.56\end{array}$ & $\begin{array}{l}0.49 \\
0.11\end{array}$ & Age \\
\hline $\begin{array}{l}2 \text { min walk distance }(\mathrm{m})^{\mathrm{e}} \\
\text { LEFT balance }{ }^{\mathrm{c}} \\
\text { LEFT chair stands } \mathrm{s}^{\mathrm{c}} \\
\text { LEFT } 8 \text { foot walk }^{\mathrm{c}} \\
\text { LEFT }^{\mathrm{c}} \\
\text { HOME FAST (number of hazards) }_{\text {CESD }^{\mathrm{a}}}\end{array}$ & $\begin{array}{l}127(39.62) \\
3.39(1.02) \\
2.44(1.20) \\
3.47(0.83) \\
9.30(2.44) \\
4.87(2.39) \\
9.8(10.77)\end{array}$ & $\begin{array}{l}125.58(41.06) \\
3.46(0.95) \\
2.36(1.23) \\
3.40(0.90) \\
9.22(2.52) \\
5.11(2.27) \\
9.73(10.61)\end{array}$ & $\begin{array}{c}125.0(40.2) \\
3.4(1.0) \\
2.4(1.5) \\
3.3(1.1) \\
9.2(3.0) \\
3.8(2.4) \\
9.3(9.6)\end{array}$ & $\begin{array}{l}126.3(41.0) \\
3.3(1.2) \\
2.6(1.5) \\
3.3(1.1) \\
9.2(3.4) \\
4.1(2.3) \\
8.8(9.7)\end{array}$ & $\begin{array}{l}0.00 \\
4.14 \\
1.01 \\
0.00 \\
0.42 \\
0.86 \\
1.32\end{array}$ & $\begin{array}{l}0.96 \\
0.04 \\
0.32 \\
0.94 \\
0.52 \\
0.35 \\
0.25\end{array}$ & $\begin{array}{l}\text { Age, group } \times \text { age } \\
\text { Age Adjusted } B=-0.82 \\
\text { Age } \\
\text { Age, group } \times \text { age } \\
\text { Age, group } \times \text { age } \\
\text { Age }\end{array}$ \\
\hline $\begin{array}{l}\text { Self-management subscales } \\
\text { Time spent stretching or strengthening (min) } \\
\text { Time spent in aerobic exercise (min) } \\
\text { Cognitive symptom management score } \\
\text { Mental stress management score } \\
\text { Tangible help score } \\
\text { Emotional support score } \\
\text { Health education score } \\
\text { Exercise program score } \\
\text { Communication with physician score } \\
\text { Self-efficacy total }\end{array}$ & $\begin{array}{c}30.49(55.71) \\
84.38(89.50) \\
1.13(0.88) \\
1.59(0.67) \\
0.67(1.00) \\
0.08(0.27) \\
1.17(0.46) \\
1.39(0.94) \\
2.57(1.42) \\
76.46(15.21)\end{array}$ & $\begin{array}{c}39.93(57.65) \\
103.21(92.89) \\
1.17(0.94) \\
1.65(0.67) \\
0.56(0.91 \\
0.12(0.33) \\
1.17(0.58) \\
1.48(1.05) \\
2.64(1.32) \\
77.43(16.27)\end{array}$ & $\begin{array}{c}40.6(54.1) \\
80.5(89.0) \\
1.3(1.0) \\
1.6(.7) \\
0.5(1.1) \\
0.1(0.2) \\
1.2(0.6) \\
1.4(0.8) \\
3.0(1.3) \\
79.7(16.0)\end{array}$ & $\begin{array}{c}41.9(58.6) \\
94.4(98.9) \\
1.2(1.0) \\
1.6(0.7) \\
0.4(0.8) \\
0.1(.2) \\
1.1(0.5) \\
1.4(0.9) \\
2.7(1.4) \\
79.5(15.6)\end{array}$ & $\begin{array}{l}0.08 \\
0.21 \\
1.03 \\
1.29 \\
0.52 \\
0.39 \\
0.53 \\
0.47 \\
3.35 \\
0.51\end{array}$ & $\begin{array}{l}0.78 \\
0.64 \\
0.31 \\
0.26 \\
0.45 \\
0.53 \\
0.47 \\
0.49 \\
0.07 \\
0.47\end{array}$ & $\begin{array}{l}\text { Age } \\
\text { Age } \\
\text { Age } \\
\text { Age } \\
\text { None } \\
\text { Age } \\
\text { Age }\end{array}$ \\
\hline $\begin{array}{l}\text { Caregiver scales } \\
\text { Caregiver strain Index } \\
\text { Caregiver self-rated burden } \\
\text { SF-36 Physical component } \\
\text { SF-36 mental component } \\
\text { Priority (high risk score, low FDI function } \\
\text { score, or fall) }\end{array}$ & $\begin{array}{l}2.67(2.87) \\
34.22(37.82) \\
45.85(13.88) \\
52.86(10.46) \\
56\end{array}$ & $\begin{array}{c}5.15(3.56) \\
38.79(40.69) \\
47.49(10.80) \\
52.84(12.27) \\
52\end{array}$ & $\begin{array}{l}n=6 \\
2.5(1.6) \\
30.2(33.2) \\
41.4(14.9) \\
52.1(7.8)\end{array}$ & $\begin{array}{l}n=10 \\
5.1(2.3) \\
36.6(25.2) \\
46.4(10.3) \\
48.3(14.6)\end{array}$ & $\begin{array}{l}1.73 \\
0.00 \\
1.74 \\
0.00\end{array}$ & $\begin{array}{l}0.24 \\
0.98 \\
0.23 \\
0.95\end{array}$ & \\
\hline
\end{tabular}


Table 5 Patient satisfaction questionnaire (PSQ-18) revised

\begin{tabular}{|c|c|c|c|c|}
\hline \multirow[t]{2}{*}{ Subscale } & \multicolumn{2}{|l|}{ Mean (SD) } & \multirow[t]{2}{*}{$t$} & \multirow[t]{2}{*}{$P$} \\
\hline & $\begin{array}{l}\text { Intervention } \\
(n=132)\end{array}$ & $\begin{array}{l}\text { Control } \\
(n=139)\end{array}$ & & \\
\hline General satisfaction & $3.6(0.8)$ & $3.2(0.5)$ & -4.69 & 0.00 \\
\hline Technical quality & $3.6(0.6)$ & $3.3(0.5)$ & -5.25 & 0.00 \\
\hline Interpersonal manner & $4.1(0.7)$ & $3.6(0.7)$ & -6.26 & 0.00 \\
\hline Communication & $3.9(0.7)$ & $3.5(0.6)$ & -5.13 & 0.00 \\
\hline Financial aspects & $3.7(0.9)$ & $3.4(0.8)$ & -2.98 & 0.00 \\
\hline Time spent & $3.8(0.7)$ & $3.4(0.6)$ & -5.57 & 0.00 \\
\hline Accessibility & $3.6(0.6)$ & $3.3(0.6)$ & -3.51 & 0.00 \\
\hline
\end{tabular}

of evidence of change within or between the groups may be due to the lack of sensitivity of change of the SF-36 in this population or a lack of potency of the rehabilitation intervention to address the issues measured by the SF-36. The participants in this study had lower scores on the physical functioning component of the SF-36 $($ mean $=42)$ compared with Canadian norms $($ mean $=50.5)$ which indicates that they were more compromised in the area of physical functioning (Hopman et al., 2000, 2006).

All of the participants had at least one chronic disease and although people with chronic diseases may be a homogenous group in terms of symptoms, they may be heterogeneous in type and severity of impairment that might have accounted for our inability to detect change. The LLFDI may also have not been sufficiently responsive to detect changes in this population; there are no published trials using this measure.

There are several limitations associated with the study. In all, $78 \%$ of the sample received the SM intervention either in a group or individual format; there might have been greater adherence to the intervention if there had been a run-in phase to the trial. However, a sub-analysis that examined compliers (persons who received at least four of the six self-management workshops) to the intervention did not change the results. The CDSMP was offered without the wider support of the other components of the comprehensive chronic illness model developed by Wagner with the support of The Robert Wood Johnson Foundation. The model includes a team approach towards SM and community resources, improved delivery system design, decision support, and policies to support this approach (Wagner et al., 1996; Wagner, 1998, 2001). This suggests a potential need for an approach to SM that integrates all members of the healthcare team. A high proportion of treatment time delivered by physiotherapy was acupuncture to address pain; this may have resulted in these participants taking a more passive approach to managing their condition. This type of multi-component intervention is a complex intervention where there are several interacting components and there are a number of behaviours required by persons receiving and delivering the intervention and a degree of flexibility or tailoring of the intervention is permitted (Craig et al., 2008). The evaluation of this type of intervention is also complex in terms of documenting the fidelity of the intervention, the standardization of the various components and the process of delivery and determining the most efficient outcomes. It would also be optimal to be able to identify the 'active ingredients' that contributed to the differences between the groups. Given the complexity of the sample and the results of the study where the findings reflect differences in satisfaction and some health service utilization, but not function or health status, it may be that patients perceive changes, which relate to quality of life and these along with patient-specific measures would be more appropriate as primary endpoints for these trials. Generalizability of results is limited to persons with the documented chronic illnesses who have at least four annual visits to their family physician. It was not feasible for participants to be blinded to the intervention.

The burgeoning impact of chronic disease means that interventions that examine approaches to management will increase. Educational, self-management, and rehabilitation interventions typically show small-to-medium effects that are often difficult to reveal in studies occurring in ecologically valid environments in which there is a lot of noise. Rehabilitation has a major contribution to offer for persons with chronic illness in primary care where multi-component interventions are required to address the multiple risk factors associated with the prognosis of these patients (Tinnetti and Fried, 2004; Tinnetti et al., 2004; Allore et al., 2005). Providing rehabilitation within the primary care team will increase equity to this service for persons who have not previously had access because they have been uninsured 
(Richardson et al., 2006). In a healthcare system oriented to acute care, persons with chronic illness may be at a lower priority for receiving healthcare interventions that may be partly due to difficulty in accessing services (Wilson et al., 2003). Rehabilitation services may be particularly difficult to access for persons with chronic illness since they are not publicly funded outside the hospital system. Future research needs to include patients in middle age with chronic disease as they have often been omitted from clinical trials (Coleman et al., 1999; Reuben et al., 1999). This study has shown changes associated with satisfaction, self-efficacy, and healthcare utilization. Future research needs to examine which patient groups show positive responses to rehabilitation and self-management and need to focus on selecting or developing highly sensitive measures of functioning to determine whether in fact changes in function can occur with these interventions.

\section{Acknowledgements}

This study was funded by a grant from the MOHLTC through the Primary Health Care Transitions Fund, trial registration id number NCT00229957.

\section{References}

Allore, H.G., Tinneti, M., Gill, T.M. and Peduzzi, P.N. 2005: Experimental designs for multicomponent interventions among persons with multifactorial geriatric syndromes. Clinical Trials 2, 13-21.

Anderson, R. and Wagner, E. 2003: Chronic illness management: what is the role of primary care? Annals Internal Medicine 138, 256-61.

Barr, V., Robinson, S., Marin-Link, B., Underhill, L., Dotts, A., Ravensdale, D. and Salivaras, S. 2003: The expanded chronic care model: an integration of concepts and strategies from population health promotion and the chronic care model. Hospital Quarterly 7, 73-82.

Beck, A., Scott, J., Williams, P., Robertson, B., Jackson, D., Gade, G. and Cowan, P. 1997: A randomized trial of group outpatient visits for chronically ill older HMO members: the cooperative health care clinic. Journal of the American Geriatrics Society 45, 543-49.

Boult, C., Boult, L., Morishita, L., Dowd, B., Kane, R. and Urdangarin, C. 2001: A randomized clinical trial of outpatient geriatric evaluation and management. Journal of the American Geriatrics Society 49, 351-59.
Boult, L., Boult, C., Pirie, P. and Pacala, J.T. 1994: Test-retest reliability of a questionnaire that identifies elders at risk for hospital admission. Journal of the American Geriatrics Society 42, 707-11.

Brazier, J., Harper, R., Jones, N., O'Cathain, A., Thomas, K., Usherwood, T. and Westlake, L. 1992: Validation of the SF36 health survey questionnaire: a new outcome measure for primary care. British Medical Journal 305, 160-64.

Burns, R., Nichols, L., Martindale-Adams, J. and Graney, M. 2000: Interdisciplinary geriatric primary care evaluation and management: two year outcomes. Journal of the American Geriatrics Society 48, 8-13.

Butland, R.J., Pang, C., Gross, E., Woodcock, A.A. and Geddes, D.M. 1982: Two-, six-, and twelve-minute walk test in respiratory disease. British Medical Journal 284, 1607-608.

Coleman, E., Grothaus, L., Sandhu, N. and Wagner, E. 1999: Chronic care clinics: a randomized controlled trial of a new model of primary care for frail older adults. Journal American Geriatrics Society 47, 1-18.

Coleman, E., Wagner, E., Grothaus, L., Hecht, J., Savarino, J. and Buchner, D. 1998: Predicting hospitalization and functional decline in older health plan enrollees: are administrative data as accurate as self-report? Journal of the American Geriatrics Society 46, 419-25.

Craig, P., Dieppe, P., MacIntyre, S., Michie, S., Nazareth, I. and Pettigrew, M. 2008: Developing and evaluating complex interventions: the new Medical Research Council Guidance. British Medical Journal 337, 979-83.

Dubois, N. 2003: An overview of chronic disease prevention. Ontario health promotion E-Mail bulletin no. 312.1.

Franks, P., Nutting, P. and Clancy, C. 1993: Health care reform, primary care, and the need for research. Journal of the American Medical Association 270, 1449-53.

Grumbach, K. and Bodenheimer, T. 2002: A primary care home for Americans: putting the house in order. Journal of the American Medical Association 288, 889-93.

Guralnik, J., Simonsick, E., Ferrucci, L., Berkman, L., Blazer, G. and Wallace, P. 1994: A short physical performance battery assessing lower extremity function: association with self-reported disability and prediction of mortality and nursing home admission. Journals of Gerontology 2, M85-94.

Haley, S., Jette, A., Coster, W., Kooyoomijian, J.T., Levenson, S. and Ashba, J. 2002: Late life function and disability instrument. II development and evaluation of the function component. Journal of Gerontology A Biological Science 57A, M209-16.

Hall, J., Milburn, M.A. and Epstein, A.M. 1993: A causal model of health status and satisfaction with medical care. Medical Care 31, 84-94.

Hayward, R., Bernard, A., Freeman, H. and Corey, C. 1991: Regular source of ambulatory care and access to health services. American Journal Public Health 81, 434-38.

Health Canada. 2001: About primary care. Ottawa: Health Canada. Retrieved 14 May 2009 from http://www.hc-sc. gc.ca/hcs-sss/prim/about-apropos-eng.php 
Hemingway, H., Stafford, M., Stanfield, S., Shipley, M. and Marmot, M. 1997: Is the SF-36 a valid measure of change in population health? Results from the Whitehall II study. British Medical Journal 315, 1273-79.

Hopman, W., Berger, C., Joseph, L., Towheed, T., VandenKerhof, E., Anastassiades, T., Adachi, J.D., Ioannidis, G., Brown, J.P., Hanley, D.A. and Papadimitropoulos, E.A., CaMos Research Group. 2006: The natural progression of health-related quality of life: results of a five-year prospective study of SF36 scores in a normative population. Quality of Life Research 15, 527-36.

Hopman, W., Towheed, T., Anastassiades, T., Tenenhouse, A., Poliquin, S., Berger, C., Joseph, L., Brown, J.P., Murray, T.M., Adachi, J.D., Hanley, D.A. and Papadimitropoulos, E.A., CaMos Research Group. 2000: Canadian normative data for the SF-36 health survey. Canadian multicentre osteoporosis study research group. Canadian Medical Association Journal 163, 265-71.

Hurley, R., Freund, D. and Taylor, D. 1989: Emergency room use and primary care case management: evidence from four medicaid demonstration programs. American Journal Public Health 79, 843-46.

Jette, A.M., Haley, S.M., Coster, W.J., Kooyoomijian, J.T., Levenson, S. and Ashba, J. 2002: Late life function and disability instrument I. Development and evaluation of the disability component. Journal of Gerontology A: Biological Science 57A, M209-16.

Keith, R.A. 1998: Patient satisfaction and rehabilitation services. Archives Physical Medicine and Rehabilitation 79, 1122-28.

Landon, B.E., LeRoi, S., Hicks, M.D., O'Malley, J., Lieu, T., Keegan, T., McNeil, B.J. and Guadagnoli, E. 2007: Improving the management of chronic disease at community health centres. New England Journal of Medicine 356, 921-34.

Leveille, S., Wagner, E., Davis, C., Grouthaus, L., Wallace, J., LoGerfo, M. and Kent, D. 1998: Preventing disability and managing chronic illness in frail older adults: a randomized trial of a community-based partnership with primary care. Journal of the American Geriatrics Society 46, 1191-98.

Lorig, K., Stewart, A., Ritter, P. et al. 1996: Outcome measures for health education and other health care interventions. Thousand Oaks, CA: Sage Publications.

Mackenzie, L., Byles, J. and Higginbotham, N. 2000: Designing the home falls and accidents screening tool (HOME FAST): selecting the item. British Journal of Occupational Therapy 63, 260-69.

Mackenzie, L., Byles, J. and Higginbotham, N. 2002a: Professional perceptions about home safety: crossnational validation of the Home Falls and Accidents Screening Tool (HOME FAST). Journal of Allied Health 31, 22-28.

Mackenzie, L., Byles, J. and Higginbotham, N. 2002b: Reliability of the Home Falls and Accidents Screening Tool (HOME FAST) for identifying older people at increased risk of falls. Disability and Rehabilitation 24, 266-74.

Primary Health Care Research \& Development 2010; 11: 382-395
Marriot, J. and Mable, A.L. 2000: Health policy and communications branch. Ottawa: Health Canada, 1-117.

Marshall, M. and Hays, R. 1994: The patient satisfaction questionnaire short-form (PSQ-18). Santa Monica: Rand Corporation.

Moore, G. and Showstack, J. 2003: Primary care medicine in crisis: toward reconstruction and renewal. Annals of Internal Medicine 138, 244-47.

Morishita, L., Boult, C., Boult, L., Smith, S. and Pacala, J. 1998: Satisfaction with outpatient geriatric evaluation and management. The Gerontologist 38, 303-308.

Pacala, J., Boult, C. and Boult, L. 1995: Predictive validity of a questionnaire that identifies older persons at risk for hospital admission. Journal of the American Geriatrics Society 43, 374-77.

Pincus, T. 2002: Limitations of randomized clinical trials in chronic diseases: explanations and recommendations. Advances 18, 14-21.

Post, M., Festen, H., van de Port, I.G. and Visser-Meily, J.M. 2007: Reproducibility of the caregiver strain index and the caregiver reaction assessment in partners of stroke patients living in the Dutch community. Clinical Rehabililtation 21, 1050-55.

Rantanen, T., Volpato, S., Ferrucci, L., Heikkinen, E., Fried, L. and Gurlanik, J. 2003: Handgrip strength and cause-specific and total mortality in older disabled women: exploring the mechanism. Journal of the American Geriatrics Society 51, 636-41.

Reuben, D., Frank, J., Hirsch, S., McGuigan, K. and Maly, R. 1999: A randomized clinical trial of outpatient comprehensive geriatric assessment coupled with an intervention to increase adherence to recommendations. Journal of the American Geriatrics Society 47, 269-76.

Richardson, J., Letts, L., Chan, D., Baptiste, S., Edwards, M., Coman, L., Price, D., Hilts, L., Stratford, P. and Law, M. 2006: Multidisciplinary approach to primary care not "twotiered". Ontario Medical Review July/August, 9-10.

Robinson, B. 1983: Validation of a caregiver strain index. Journal of Gerontology 38, 344-48.

Schraeder, C., Shelton, P. and Sager, M. 2001: The effects of a collaborative model of primary care on the mortality and hospital use of community-dwelling older adult. Journal of Gerontology: Medical Sciences 56A, M106-12.

Scott, J.C., Conner, D.A., Venohr, I., Gade, G., Mackenzie, M., Kramer, A.M., Bryant, L. and Beck, A. 2004: Effectiveness of a group outpatient visit model for chronically ill older health maintenance organization members: a 2-year randomized trial of the cooperative health care clinics. Journal of the American Geriatrics Society 52, 1463-70.

Tinnetti, M. and Fried, T. 2004: The end of the disease era. The American Journal of Medicine 116, 179-85.

Tinnetti, M., Bogardus, S.T. and Agostini, J.V. 2004: Potential pitfalls of disease-specific guidelines for patients with multiple conditions. New England Journal of Medicine 348, 1556-64.

Wagner, E.H. 1998: Chronic disease management: what will it take to improve care for chronic illness? Effective Clinical Practice 1, 2-4. 
Wagner, E.H., Glascow, R.E., Davis, C., Bonomi, A.E., Provost, L., McCulloch, D., Carver, P. and Sixta, C. 2001: Quality improvement in chronic illness care: a collaborative approach. 27, 63-80.

Wagner, E.H., Austin, B.T. and Von Korff, M. 1996: Organizing care for patients with chronic illness. The Milbank Quarterly 74, 511-44.

Way, D., Jones, L., Baskerville, B. and Busing, N. 2001: Primary health care services provided by nurse practitioners and family physicians in shared practice. Cananian Medical Association Journal 165, 1210-14.
Weinberger, M., Oddone, E. and Henderson, W. 1996: Does increased access to primary care reduce hospital readmission? New England Journal of Medicine 334, 1441-47.

Wilson, A., Oldenberg, B.F. and Lopez, A.D. 2003: Targeted approaches for reducing inequities in chronic disease. Medical Journal of Australia 179, 222-23.

World Health Organization. 2007: Facts related to chronic diseases and the WHO global strategy on diet, physical activity and health. Geneva, Switzerland. Retrieved 5 August 2009 from http://www.who.int/dietphysicalactivity/ publications/facts/chronic/en/index.html. 